\title{
Two-way self-punitive locomotor behavior
}

\author{
NEWELL K. EATON and CHARLES R. CROWELL \\ University of Oregon Medical School, Portland, Oregon 97201
}

\begin{abstract}
The effect of an explicit buzzer CS upon self-punitive locomotor behavior was investigated in an experiment utilizing a fully automated two-way locomotor device. Two groups of rats received shock-escape training and extinction, with or without the CS. During extinction, half of the animals in each group were shocked in the middle segment of the alley while the other half were given no-shock regular extinction trials. Rats trained and extinguished with the CS completed more extinction trials than those trained and extinguished without a CS, while rats punished during extinction completed more trials than rats given regular extinction trials. In addition, the punishment-produced facilitation of extinction performance was greater for rats trained and extinguished with the CS than for those without the CS.
\end{abstract}

Although the phenomenon of self-punitive or "vicious-circle" behavior has been well documented (Brown, 1969; Melvin, 1971), an inspection of this literature indicates that, with few exceptions, investigations in this area have been limited to situations involving one-way locomotor responses. This is not too surprising, however, in view of the prevalent theoretical account of self-punitive behavior initially suggested by Mowrer (1947), and expanded by Brown (1969). The Mowrer-Brown theory clearly implies that conditions leading to the maximization of conditioned fear in the starting area of an alleyway and the minimization of fear in the goal area would be most effective in the development and maintenance of self-punitive running (cf. Brown, 1969, p. 511). This suggestion is based upon the suppositions that fear serves to energize existing locomotor tendencies in the starting area, and that fear reduction in the goal area provides an important source of reinforcement for the preceding response sequence. Although these ideal conditions are usually approximated reasonably well in the typical one-way locomotor apparatus, they do not normally occur in standard twoway devices. In a two-way shuttlebox, for instance, the cues of each side of the apparatus are ambiguous since both sides serve as start and as goal areas on alternate trials. Since competing approach and avoidance responses, as well as fear, may become conditioned to both sets of cues, circumstances are not optimal for the production of vicious-circle behavior. In addition, intertrial confinement of the subject to the start-goal

This research, completed at the University of Oregon Medical School, was supported by a National Institute of Mental Health Research Grant (MH 23607) awarded to Judson S. Brown. Requests for reprints should be sent to Newell K. Eaton, US Army Research Institute, Ft. Knox, Kentucky 40121. The findings in this report are not to be construed as an official Department of the Army position, unless so designated by other authorized documents. Charles $R$. Crowell is now at the Department of Psychology, University of Notre Dame, Notre Dame, Indiana. Judson S. Brown sponsors this paper and takes full editorial responsibility for its contents. areas should lead to the partial extinction of fear to their cues, further decreasing the likelihood of self-punitive running (O'Neil, Skeen, \& Ryan, 1970). These factors may also be responsible, in part, for the difficulties encountered in attempts to maintain two-way escape behavior during nonshock extinction periods, and for the relative difficulty with which two-way shuttle avoidance responses are acquired (e.g., Theios, Lynch, \& Lowe, 1966). In the present experiment, self-punitive locomotor behavior was examined in the context of a two-way locomotor apparatus (Crowell \& Eaton, 1974) employing two-level trapdoor-floored start-goal compartments designed to preserve maximum dissimilarity of start and goal areas, to preclude the occurrence of shocks in the presence of goal cues, and to reduce or eliminate the extinction of fear to starting-area cues during pretrial confinement.

A second purpose of this study was to assess the effect of an explicit (buzzer) CS on the establishment of self-punitive behavior. Although discrete CSs have been employed in many studies of vicious-circle behavior, the only systematic investigation of the effects of such a stimulus in this context is contained in an unpublished study by Fowler and his associates (cited in Fowler, 1971 , p. 585). Fowler observed that self-punitive behavior in a one-way alley was enhanced by the addition of an explicit CS to the complex of startbox cues. Such a result is consistent with several fear-conditioning interpretations.

The present experiment involved a 2 by 2 factorial design in which the presence or absence of an explicit CS throughout acquisition and extinction was combined with punished and nonpunished extinction conditions in a two-way locomotor training apparatus.

\section{METHOD}

\section{Subjects}

The subjects were 32 naive female albino rats (SpragueDawley derivatives), 90-120 days old at the start of the experiment. They were obtained from Simonsen Laboratories, Gilroy, California. They were housed individually under conditions of 
constant light and temperature and had free access to food and water throughout the experiment.

\section{Apparatus}

The apparatus, described elsewhere (Crowell \& Eaton, 1974), consisted of two identical grid-floored $48-\mathrm{cm}$-long start-goal segments, each of which was closed on one end and connected at the opposite open end to a grid-floored $61-\mathrm{cm}$ straight alley segment, thus forming an alleyway $157 \mathrm{~cm}$ long. A $23-\mathrm{cm}-$ long aluminum flap was hinged to one side wall $15 \mathrm{~cm}$ above the grid at the closed end of each of the start-goal segments. Each flap, when raised to a horizontal position, served as the trapdoor floor of an elevated goal compartment into which a rat could jump to terminate a trial. Following an intertrial interval, the flap was released and swung down to a vertical position, dropping the rat onto the grid-floor starting area, and beginning the next trial. A rat's entire response sequence involved being dropped from the goal area into the starting area of one startgoal segment, traversing the alley, and jumping up onto the trapdoor-floored goal area of the other start-goal segment. On the next trial, the sequence of events was reversed and the animal was required to traverse the alley in the opposite direction. Thus, while the subject ran through the alley in both directions, its terminal jumping response always carried it into a goal region where shock never occurred. During normal operation of the apparatus, the flaps were raised and released automatically by means of solenoids and associated programming equipment. The walls of each of the goal areas were covered with vertical $2.54-\mathrm{cm}$-wide black and white stripes to differentiate them from those of the starting areas and alley. Throughout each trial and during the subsequent intertrial period, the goal area into which the rat leaped was illuminated by a 6-V lamp.

Electric shock was delivered to the grid floor and stainless steel walls of the apparatus by a Grason-Stadler shock generator/ scrambler (Model 700). An ac buzzer (Potter \& Brumfield, Model BU-120 ac) was affixed to the middle of one outside wall of the alley segment $35 \mathrm{~cm}$ above the grid floor. This buzzer was employed as an explicit CS in some treatment conditions. The increment in acoustic energy provided by the buzzer was $22 \mathrm{~dB}$ above ambient sound level (67 dB as measured on the $\mathrm{C}$ scale of an H. H. Scott sound-level meter, Model 450B).

\section{Procedure}

All acquisition and extinction trials were administered in 1 day with a fixed intertrial interval of $60 \mathrm{sec}$. Acquisition for each rat consisted of seven shaping trials during which the alley was operated by hand and 56 fully automated escape trials. During acquisition, shock was delivered to the walls and grid floor of the entire alley and starting areas. On the first three shaping trials, a wooden ramp was placed between the grid floor and the trapdoor floor of the to-be-entered goal area. The subject was required to traverse the alley and run up the ramp into the goal area in order to escape shock. The nominal shock intensity on these trials was $1.0 \mathrm{~mA}$. For the last four shaping trials, a wooden block was placed under the trapdoor floor of the goal compartment, and the ramp was removed. The block prevented the rat from running all the way under the flap rather than jumping onto it. During the course of these trials, the block was moved further and further under the trapdoor floor of the appropriate goal compartment in order to approximate gradually the conditions to be encountered on fully automated trials. The shock intensity on these and all remaining trials was .6 mA. Starting with Trial 8 , the trapdoor floors were raised and released automatically, and the block was removed.

Prior to initiation of training, each subject was randomly assigned either to a buzzer (B) or no-buzzer (NB) treatment condition. During both acquisition and extinction, the buzzer was energized $3 \mathrm{sec}$ prior to floor release for rats receiving the B treatment and de-energized when they completed the terminal jumping response. Rats assigned to the NB treatment condition were never exposed to the buzzer.

Immediately following acquisition, half of the subjects in each of the $B$ and NB groups were assigned regular extinction (RE) conditions in which shock was discontinued throughout the alley. The remaining rats received a punished-extinction (PE) treatment in which shock $(.6 \mathrm{~mA})$ was present on each trial throughout the $61-\mathrm{cm}$ alley segment, but was not present in either start-goal segment. Extinction was continued to a maximum of 200 trials or until the rat failed to complete a trial within $120 \mathrm{sec}$ after being dropped onto the grid.

On each acquisition and extinction trial, running and jumping times were recorded. Running time was the time that the rat spent in the $61-\mathrm{cm}$ alley segment, while jumping time was the time that the rat took to make the terminal jumping response after entering a start-goal segment.

\section{RESULTS}

\section{Acquisition}

Median running and jumping times were obtained for each rat over blocks of seven trials during acquisition and were converted to speeds in centimeters/second. Comparisons of mean-median running and jumping speeds obtained from the first and last blocks of seven trials for each of the four groups indicated clearly that the performance of all groups improved during the course of acquisition. Moreover, separate 2 by 2 factorial analyses of variance (including presence or absence of the buzzer CS and regular- or punished-extinction conditions as between and pseudo-between factors, respectively) were applied to each rat's median running and jumping speeds from the last block of acquisition trials. Since none of the effects in these analyses approached significance, it is reasonable to assume that any group differences during extinction could not be attributed to differing terminal levels of acquisition performance among groups or to a pretreatment sampling bias.

\section{Extinction}

The resistance to extinction of the locomotor escape response was the measure of primary importance in this experiment. The number of trials completed by each rat during extinction, including the criterion trial on which the rat failed to jump into the goal area within $120 \mathrm{sec}$, was selected as an index of resistance to extinction. Figure 1 is a graph of the mean number of trials to extinction for each of the four groups in this experiment. It is apparent from this figure that animals punished during extinction persisted longer in locomotor behavior than did nonpunished subjects, regardless of the presence or absence of the buzzer CS. This effect is exemplary of the often-reported phenomenon of selfpunitive locomotor behavior. Likewise, Figure 1 indicates that the presence of the buzzer CS during both acquisition and extinction prolonged the extinction of the escape response, relative to no-buzzer treatments, irrespective of regular- or punished-extinction conditions. Additionally, the facilitative effect of 


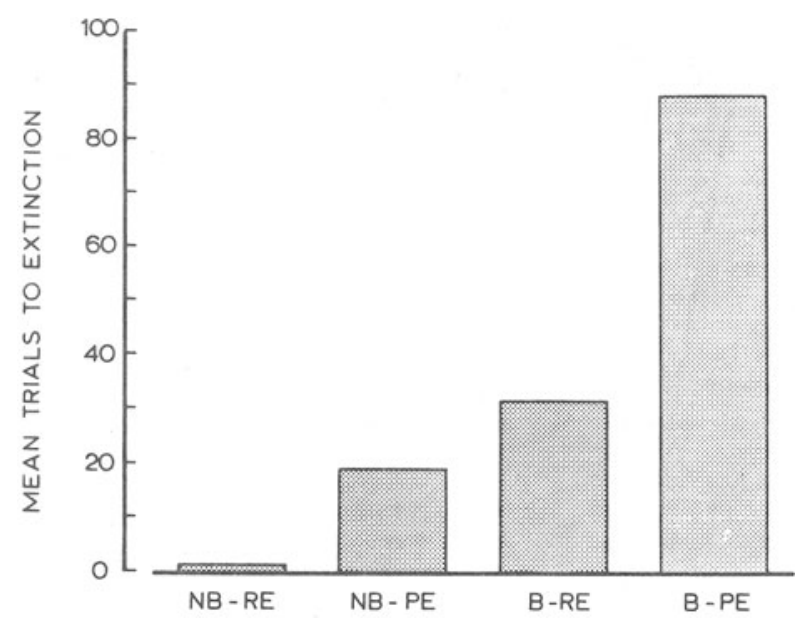

Figure 1. Mean trials to extinction for each of the four groups resulting from the combination of buzzer (B) or no-buzzer (NB) and punished- (PE) or regular-extinction (RE) treatments.

punishment was greater for buzzer than no-buzzer subjects.

These visual impressions were supported by the results of a nonparametric analysis appropriate for a factorial design following the procedure suggested by Bradley (1968, pp.138-141). Both the main effects of Buzzer $(\mathrm{W}=48)$, Punishment Treatments $(\mathrm{W}=48)$, and the Buzzer by Punishment interaction $(\mathrm{W}=48)$ proved to be reliable $(p<.025)$.

Plots of both running and jumping speeds during extinction (not shown) were in complete accord with the trials to extinction data. These speed data were not subjected to statistical analysis, however, since the rapid extinction of some subjects would have necessitated the use of an untenably large number of pseudospeed scores.

\section{DISCUSSION}

The results of this study are consistent with previous findings that punishment may enhance the resistance to extinction of locomotor escape reactions; punished rats in this experiment persisted in locomotor behavior for more trials during extinction than their nonpunished counterparts despite equal levels of performance attained by all groups during acquisition. This finding represents the first report of a facilitative effect of shock during the extinction of a two-way escape response. Although a punishment-extinction procedure has been employed in conjunction with a two-way locomotor response in at least two previous studies, the acquisition regimen in these experiments consisted of avoidance training. Unfortunately, the findings of these investigations are not definitive since shock enhanced resistance to extinction in one case (Solomon, Kamin, \& Wynne, 1953) but not in the other (Smith, Misanin, \& Campbell, 1966). Factors possibly relevant to this discrepancy have been discussed at length by Brown (1969).

The presence of the buzzer CS increased resistance to extinction of the escape response regardless of whether or not punishment was present in the alley. This facilitative effect of the buzzer CS during extinction cannot be attributed to higher levels of acquisition performance in the buzzer groups. Further- more, it is unlikely that the buzzer CS served as a significant source of primary drive. Subjects in Group B-RE, for example, were exposed during extinction to an escape paradigm with buzzer cessation as the reinforcer. The fact that only two of the eight rats in this group completed more than 60 trials attests to the inadequacy of buzzer termination alone in maintaining escape responding, as it should were it unconditionally aversive. In addition, it should be noted that prior to the initiation of this experiment several naive rats were given escape training using the buzzer rather than shock as a US. None of these animals learned the escape response. Taken together, these results suggest that the dynamogenic effects of the buzzer on the locomotor response during extinction derived largely from an acquired aversive or fear-arousing property of that CS presumably resulting from its association with shock in the acquisition phase for both buzzer groups, and perhaps during extinction for the B-PE group. The compound CS consisting of the buzzer and starting area cues would seem to be capable of evoking a more vigorous fear reaction and hence a stronger locomotor reaction in the buzzer groups. This interpretation of the effects of the buzzer CS is fully consistent with the Mowrer-Brown notion of self-punitive behavior. According to that view, the degree of perseveration of the locomotor response during extinction is directly related to the amount of fear elicited in the starting area of the alley at the beginning of a trial (see Galvani, 1969).

The question remains, however, as to the mechanism(s) responsible for the greater fear-arousing property of the compound of buzzer and startbox cues than of the startbox cues alone. One plausible account appeals to the notion that partial extinction of fear of the apparatus may take place in the intertrial intervals during the acquisition phase. Such extinction could occur for animals in the present device since access to visual alley cues was not precluded during the intertrial interval, even though the rats spent that time in a distinctive goal compartment. Extinction of fear of the buzzer could not be expected to occur during this time, however. Thus an equal degree of fear extinction to apparatus cues in all groups would result in a net fear-arousing property for the compound of buzzer and starting area cues that was greater than that of the starting area stimuli alone, assuming a simple additive relationship among associative strengths of elements of the compound CS. At the start of extinction, therefore, the compound CS with the buzzer would be more fear arousing than the stimuli consisting of apparatus cues alone. A similar prediction concerning the effectiveness of the buzzer CS compound, relative to apparatus cues alone, is suggested by a recent analysis of conditioning with compound CSs provided by Rescorla (in press) and Rescorla and Wagner (1972). These supposed differences among groups in the amount of conditioned fear aroused by their respective CS conditions might not necessarily lead to differences in performance during acquisition, however, since the primary drive provided by shock should far outweigh fear-produced drive.

The fact that the CS in the buzzer groups preceded the start of a trial (by $3 \mathrm{sec}$ ) may also be important in an interpretation of the present results. For the no-buzzer groups, the initiation of a trial was unsignaled except for temporal cues. It seems reasonable to assume that the former procedure would be more conducive to persistent locomotor behavior during extinction than would the latter, either because the process regulating increases in drive level is already in operation at the start of a trial for buzzer rats or because some postural adjustment can take place during the warning period. The use of such a warning period before each trial in the present two-way apparatus most closely resembles the typical procedures employed in studies of self-punitive behavior using the conventional straight alley (cf. Brown, Martin, \& Morrow, 1964). The foreperiod in the one-way alley consists of the interval (commonly $5-10 \mathrm{sec}$ ) from placement of the subject in the startbox to trial onset. It could be, therefore, that the effect of an explicit CS in the one-way situation would not be as great as in the present case due to the 
"built-in" warning period in the former condition necessitated by transportation of the subjects between trials.

Finally the performance superiority of the B-PE group over the B-RE group was numerically and statistically greater than that of the NB-PE group over the NB-RE group. Such a significant effect could be accounted for were the greater persistence during extinction of the B-RE rats over the NB-RE rats accepted as support for the assertion that the addition of a buzzer to starting area cues for B-RE (and B-PE) leads to stronger running tendencies in those groups. Such stronger, more dominant responses would be expected to compete more successfully with punishment-produced competing tendencies and, under conditions of shock-induced drive increments, lead to an increased likelihood of self-punitive running.

\section{REFERENCES}

Bradley, J. V.Distribution-free statistical tests. Englewood Cliffs: Prentice-Hall, 1968. Pp. 138-141.

BRown, J. S. Factors affecting self-punitive locomotor behavior. In B. A. Campbell, \& R. M. Church (Eds.), Punishment and aversive behavior. New York: Appleton-Century-Crofts, 1969.

Brown, J. S., Martin, R. C., \& Morrow, M. W. Self-punitive behavior in the rat: Facilitative effects of punishment on resistance to extinction. Journal of Comparative and Physiological Psychology, 1964, 57, 127-133.

Crowell, C. R., \& Eaton, N. K. A fully automated two-way locomotor training apparatus. Behavior Research Methods \& Instrumentation, 1974, 6, 19-22.

FowLER, H. Suppression and facilitation by response contingent shock. In F. R. Brush (Ed.), Aversive conditioning and learning. New York: Academic Press, 1971.
Galvani, P. F. Self-punitive behavior as a function of number of prior fear-conditioning trials. Journal of Comparative and Physiological Psychology, 1969, 68, 359-363.

Melvin, K. B. Vicious circle behavior. In H. D. Kimmel (Ed.), Experimental psychopathology: Recent research and theory. New York: Academic Press, 1971.

MOWRER, O. H. On the dual nature of learning - a reinterpretation of "conditioning" and "problem-solving." Harvard Educational Review, 1947, 17, 102-148.

O'Neil, H. F., Skeen, L. C., \& Ryan, F. J. Prevention of vicious circle behavior. Journal of Comparative and Physiological Psychology, 1970, 70, 281-285.

Rescorla, R. A. A model of Pavlovian conditioning. In V. S. Rusinov, (Ed.) Mechanisms of Formation and Inhibition of Conditional Reflex. Moscow: "Nauka" Academy of Sciences of the USSR, in press.

Rescorla, R. A., \& WAgner, A. R. A theory of Pavlovian conditioning: Variations in the effectiveness of reinforcement and nonreinforcement. In A. H. Black, \& W. F. Prokasy (Eds.) Classical conditioning II: Current theory and research, New York: Appleton-Century-Crofts, 1972.

Smith, N. F., Misanin, J. R., \& Campbell, B. A. Effect of punishment on extinction of an avoidance response: Facilitation or inhibition? Psychonomic Science, 1966, 4, 271-272.

Solomon, R. L., Kamin, L. J., \& Wynne, L. C. Traumatic avoidance learning: The outcomes of several extinction procedures with dogs. Joumal of Abnormal and Social Psychology, 1953, 48, 291-302.

Theios, J., Lynch, A. D., \& Lowe, W. F. Differential effects of shock intensity on one-way and shuttle avoidance conditioning. Journal of Experimental Psychology, 1966, 72, 294-299.

(Received for publication August 19, 1976.) 